\title{
Naturally occurring anti-inflammatory factors in the synovial fluids of patients with rheumatic disease and their possible mode of action
}

\author{
R. B. CAPSTICK, D. A. LEWIS, AND J. A. COSH \\ From the Pharmacology Section, Department of Pharmacy, University of Aston in Birmingham, and \\ Royal National Hospital for Rheumatic Diseases, Bath
}

\begin{abstract}
Capstick, R. B., Lewis, D. A., and Cosh, J. A. (1975). Annals of the Rheumatic Diseases, 34, 213-218. Naturally occurring anti-inflammatory factors in the synovial fluids of patients with rheumatic disease and their possible mode of action. (1) Evidence has been shown that pathological synovial fluid contained a substance capable of stabilizing rat liver lysosomes which was partly inactivated by treatment with trypsin and by storage. Such synovial fluid also appeared to contain a substance which labilized lysosomes and which was more stable than the stabilizing substance. (2) The lysosomal stabilizing substance described above was nondialysable and migrated electrophoretically with the $\alpha$ and $\beta$ globulins to which class it has been tentatively ascribed. (3) Pathological synovial fluid contained proteases which were active at acid $\mathrm{pH}$ and at neutral $\mathrm{pH}$. It also appeared to contain a substance capable of inhibiting these proteases. (4) $\alpha_{2}$-Macroglobulin has been detected in pathogenic synovial fluid.
\end{abstract}

It is well established that inflammatory exudates in animal models contain substances that inhibit inflammation (Billingham, Robinson, and Robson, 1969a, b; Di Pasquale, Girerd, Beach, and Steinetz, 1963). Since these substances are accompanied by irritants present in the exudates (Atkinson, Boura, and Hicks, 1969), it appears that the net inflammatory condition is the result of the opposing interaction of the two types of factor. Billingham and Robinson (1972) have recently isolated an anti-inflammatory protein fraction from carrageenin-induced inflammatory exudate in rats and shown that this fraction was devoid of significant irritant properties. The mode of action of these anti-inflammatory proteins is not known.

In this report we have examined the synovial fluids of patients with rheumatic disease for naturally occurring anti-inflammatory factors. In particular, we have looked for evidence of antiproteases and membrane active substances as indications in vitro of anti-inflammatory activity.

\section{Antiproteases}

Lysosomal enzymes, at least in part, are thought to be responsible for the degradation of the cartilage matrix in rheumatoid arthritis (Dingle, 1962). The presence of specific antiproteases, such as antitrypsin, in serum has been established for some time, but recently Barrett and Starkey (1973) have produced evidence that $\alpha_{2}$-macroglobulin may act as a universal antiprotease. It is well established in animal models that inflammation is accompanied by raised proteolysis and that an induction of protease inhibitors takes place during inflammation (Menkin, 1942; Ungar, 1947). It was also established that these inhibitors can modify the inflammatory response.

\section{Membrane active substances}

Luscombe (1963) and other authors have reported that lysosomal enzyme levels are raised in the synovial fluids of patients with rheumatoid arthritis. It is well established that corticosteroids and some nonsteroidal anti-inflammatory drugs stabilize lysosomes. This action has been proposed to explain at least part of the anti-inflammatory action of these drugs. There is evidence that endogenous proteins can also stabilize lysosomes in vivo (Persellin, 1972). Using the arthritic rat as a model, Collins and Lewis (1971) showed that after the administration of the adjuvant, serum lysosomal enzyme levels rose rapidly to abnormally high values. Subsequently these enzyme levels fell to 
normal but rose again with the onset of inflammation. Ignarro and Slywka (1972) showed that the initial rise of lysosomal enzyme levels was due to an increased fragility of liver lysosomes. However, Persellin (1972) has shown that this initial fragility is later abolished by the formation in vivo of a circulating high molecular weight $\alpha$-globulin with an affinity for lysosomal and erythrocyte membranes. This globulin was not an antibody and was absent from control animals.

\section{Purpose of present study}

The objects of the experiments reported in this paper were: (1) To investigate the possibility that endogenous inflammatory and anti-inflammatory factors are present in the synovial fluids of patients with rheumatic disease. (2) To investigate the nature of these factors, if present, and to determine their possible mode of action.

\section{Materials and methods}

SYNOVIAL FLUIDS AND CELLS

These were obtained from patients at the Royal National Hospital for Rheumatic Diseases, Bath, and the cells isolated from the fluids as previously described (Lewis and Day, 1972). The fluids and cells were examined as soon as possible after aspiration but where storage was necessary this was at $4^{\circ} \mathrm{C}$, and cell-free fluids after ultracentrifugation were stored at $-20^{\circ} \mathrm{C}$.

\section{ACTION OF SYNOVIAL FLUIDS ON ISOLATED RAT LIVER LYSOSOMES}

The rat liver lysosomes were isolated by methods previously described (Lewis, Symons, and Ancill, 1969) and suspended in tris-acetate buffered isotonic sucrose ( $\mathrm{pH}$ 7.4). The final protein concentration of the suspension was adjusted to $5 \mathrm{mg} / \mathrm{ml}$ (Lowry, Rosebrough, Farr, and Randall, 1951). In a typical incubation $3 \mathrm{ml}$ of the suspension was incubated with $1 \mathrm{ml}$ of synovial fluid and the volume made up to $5 \mathrm{ml}$ with buffered sucrose. The mixtures so prepared were incubated for $90 \mathrm{~min}$ at $37^{\circ} \mathrm{C}$ in a shaking reaction incubator followed by ultracentrifugation at $20000 \mathrm{~g}$ for $30 \mathrm{~min}$ to remove the lysosomes. Acid phosphatase (E.C. 3.1.3.2) activity in the supernatant was used as a marker and assayed by the method of Symons and others (1969). In the controls, synovial fluid was omitted from some flasks and lysosomes from others. In other experiments, synovial fluids were pretreated by incubation with an equal volume of $5 \% \mathrm{w} / \mathrm{v}$ trypsin for $60 \mathrm{~min}$ at $37^{\circ} \mathrm{C}$. Two $\mathrm{ml}$ of the hydrolysate were then added to $3 \mathrm{ml}$ of the lysosomal suspension and the effect of the hydrolysed fluid on the stability of the lysosomes determined as described above. In some flasks the synovial fluid was replaced by buffer in order that the direct action of trypsin on lysosomes could be determined.

SEPARATION OF PROTEINS FROM SYNOVIAL FLUID Two methods were employed.

\section{Chemical separation}

An equal volume of saturated ammonium sulphate solution was added to synovial fluid at $4^{\circ} \mathrm{C}$. The solution was stirred and allowed to stand for an hour in a refrigerator. The precipitated protein (the globulin fraction) was then removed by centrifugation. The clear supernatant was then saturated with ammonium sulphate and allowed to stand for a further hour, to precipitate the albumin fraction, and was then centrifuged again. Both fractions were separately dialysed against tris buffered sucrose $(\mathrm{pH} \mathrm{7 \cdot 4).}$

\section{Chromatographic separation}

Synovial fluid was applied to the top of a column packed with Sephadex G200 after the void volume had been 0 determined with Dextran Blue 2000. The column was eluted with tris-acetate buffer solution $(\mathrm{pH} \mathrm{7.4)}$ and the fractions collected automatically. The separation was performed at $4^{\circ} \mathrm{C}$. The fractions were assayed for protein at $280 \mathrm{~nm}$ and pooled into three main fractions containing (in order of elution) $\alpha$ and $\beta$ globulins, globulins, and albumins. The proteins present in each fraction were identified by electrophoresis in cellulose acetate strips. Each fraction prepared by both methods described above i was concentrated to small bulk by dehydration in dialysis sacs placed in Aquacide (Calbiochem) at $4^{\circ} \mathrm{C}$. The protein concentration of each solution was determined by the method of Lowry and others (1951).

ELECTROPHORESIS AND IMMUNOELECTROPHORESIS OF SYNOVIAL FLUID

Attempts to separate synovial fluid proteins on cellulose acetate strips were largely unsuccessful owing to streaking This problem was overcome by using agar gel films on microscope slides. Wells and slots were cut with a patter窟 cutter (Shandon) and the slides were developed at $2 \mathrm{~mA} / \mathrm{cm}^{+}$ in a $0.1 \mathrm{~mol} / 1$ acetate-barbiturate buffer adjusted to pH 8.6 with $\mathrm{HCl}$. Bromophenol blue was used as a marker. After development, the slides were dried with filter paper and immersed for $60 \mathrm{~min}$ in a $1 \% \mathrm{w} / \mathrm{v}$ solution of Amido Black in $7 \% \mathrm{w} / \mathrm{v}$ acetic acid and washed in $7 \%$ acetic acid until the background was clear. In the immunoelectrophoretic studies the antisera were placed in the slots and the plates allowed to stand overnight in a humidity cabinet (Shandon). The plates were then washed in saline and the precipitin lines stained with Amido Black as described above.

PREPARATION OF ANTISERA

Rabbit antisera were prepared against human synovial fluid and against rat liver lysosomal membranes that had been previously treated with human synovial fluid.* The rat liver lysosomes were incubated with synovial fluid as described above and then isolated from the suspension by ultracentrifugation. The lysosomes were washed in a large excess of saline and isolated twice to freezing and thawing and then suspended in a large excess of saline. The membranes were obtained by further ultracentrifugation.

Both the membrane preparations and the synovial fluid were emulsified with arachis oil. Two $\mathrm{ml}$ of the emulsions were injected into the footpads of rabbits and at various intramuscular sites. The treatment was repeated a month later and blood samples taken from an ear vein after a further two weeks. The blood was allowed to clot and the serum removed by decanting.

* Rabbit antisera against human $\alpha_{2}$-macroglobulin were purchased from Mercia Diagnostics Ltd., Watford, Herts. 
PROTEASE DETERMINATIONS IN SYNOVIAL FLUIDS Acid protease activity was assayed at $\mathrm{pH} 4.0$ by the method of Anson (1938) and neutral protease at $\mathrm{pH} \mathrm{7.8}$ using Hide Powder Azure (Calbiochem) as substrate by the method of Rinderknecht, Geokas, Silverman, Lillard, and Haverback (1968).

In order to examine the synovial fluids for antiprotease action against acid protease, synovial fluid cells were removed from the fluids by centrifugation and lysed by freezing and thawing in the appropriate buffer solution. In the samples taken at least $90 \%$ of the cell types were polymorphonuclear leucocytes. The acid protease activities of the lysates were determined. In some experiments equal volumes of synovial fluid were added to the cell lysate and the protease activity determined. The cell suspension was omitted from the controls.

\section{Results}

ACTION OF SYNOVIAL FLUID ON LYSOSOMES

From Table I it will be seen that the results were different for different patients. Clearly opposing effects were observed in that some of the fluids had an irritant action on lysosomes and others had a stabilizing action. The effect of trypsin-treated synovial fluid on lysosomes is shown in Table II. Trypsin undoubtedly causes lysis of the lysosomes but trypsin and synovial fluid combined had a stronger lytic action than the sum of trypsin and synovial fluid separately. One possible explanation for this effect is that pretreatment of the synovial fluid with trypsin has destroyed protective substances originally present in the fluids. Some evidence for this view is provided by the results in Table I. The stabilizing action of samples 14,15 , and 16 was far greater when the fluid was fresh than when the samples were 6 months old, although stored deep frozen. It appears that over the 6 months some destruction of the lysosomal membrane stabilizing factor has occurred, possibly by autoproteolysis.

Dialysis of the synovial fluid before incubation with lysosomes did not abolish or reduce the stabilizing action of the fluid.

Table I Lytic and stabilizing factors in pathological synovial fluid (from knee)

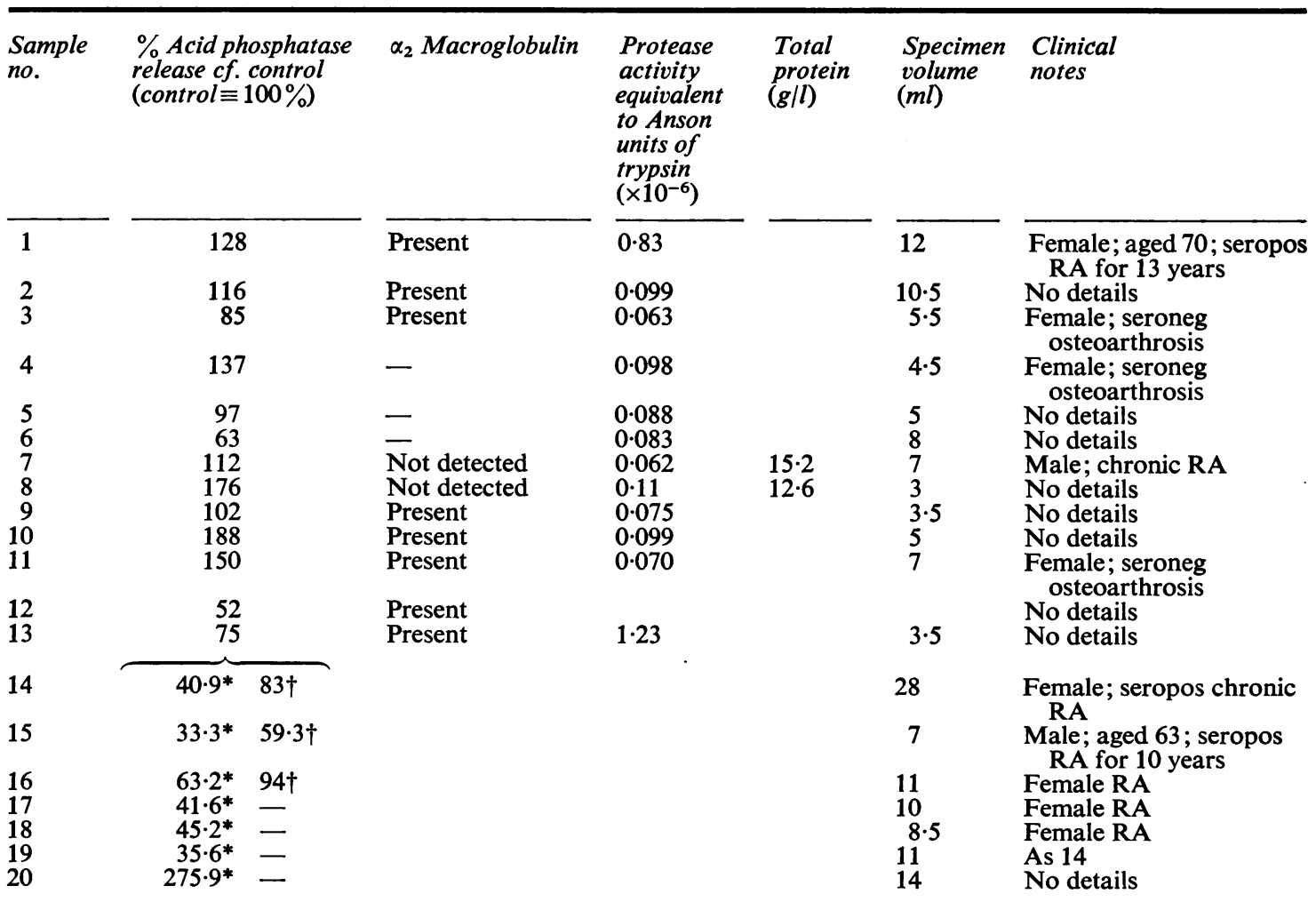

* Freshly drawn ultracentrifuged sample.

$\dagger$ Same samples after 6 months' storage at $-20^{\circ} \mathrm{C}$. Samples 1 to 13 , ultracentrifuged to remove cells, then stored at $-20^{\circ} \mathrm{C}$. 
Table II Action of trypsin-treated synovial fluid on lysosomes*

Sample 11

Lysosomes + synovial fluid

Lysosomes $+0.25 \%$ trypsin

Lysosomes + synovial fluid $+0.25 \%$ trypsin

Total (frozen and thawed lysosomes)

Sample 20

Lysosomes + synovial fiuid

Lysosomes $+1 \%$ trypsin

Lysosomes + synovial fluid $+1 \%$ trypsin

Total (frozen and thawed lysosomes)
$\%$ Acid phosphatase released compared with control value of 100

130
323
672
1840

1615

* The results are the mean values of three determinations.

\section{STABILIZING ACTION OF SYNOVIAL FLUID PROTEINS ON LYSOSOMES}

These results are given in Table III. Where the proteins were isolated from synovial fluid by ammonium sulphate precipitation, the globulin fraction has had a greater stabilizing action than the albumin fraction. A similar result was obtained when the proteins were separated by gel filtration. This experiment showed that the stabilizing action of the proteins was largely confined to the high molecular weight proteins (the $\alpha$ and $\beta$ globulin fraction). The $\gamma$ globulin fraction and the albumin fraction had little stabilizing action.

\section{ELECTROPHORESIS AND IMMUNOELECTRO-} PHORESIS OF SYNOVIAL FLUID PROTEINS

The pattern obtained on staining agar plates with Amido Black is shown in Figure $a$. The precipitin pattern obtained when the plates were treated with rabbit antisera against human synovial fluid is shown in Figure $b$. When the plates were treated with

Table III Action of proteins isolated from synovial fluid on lysosomes*

Sample 12

Ammonium sulphate precipitation

Albumin fraction

Globulin fraction

Sephadex G200 separation

$\alpha$ and $\beta$ globulin fraction

Globulin fraction

Albumin fraction

* Each experiment utilized the protein isolated from $2 \mathrm{ml}$ synovial fluid. rabbit antisera against rat liver lysosomes that had been treated with human synovial fluid two precipitin lines were obtained (Figure $c$ ). Clearly proteins in the $\alpha$ and $\beta$ globulin class had associated with the rat liver lysosomes. No evidence was obtained for $\gamma$-globulins being associated with the lysosomal membranes and this result is consistent with the results obtained when the gel filtration protein fractions were incubated with lysosomes. The presence of $\alpha_{2}$-macroglobulin was detected in blood and in some synovial fluide but was absent in others (see Table I).
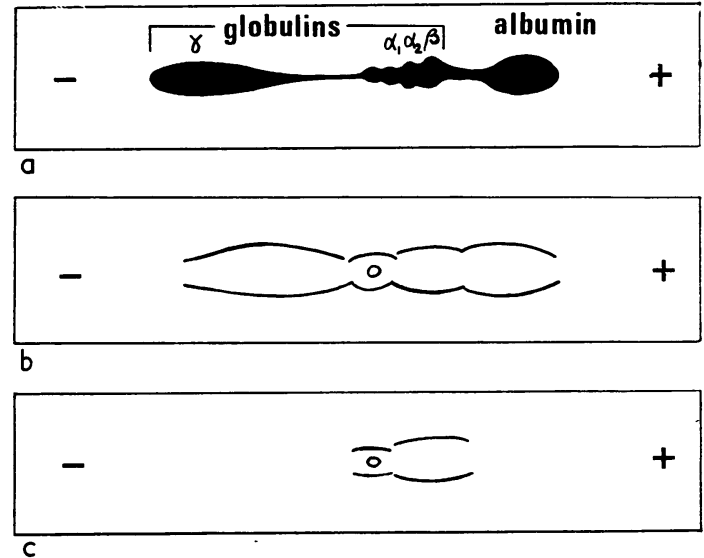

FIGURE (a) Pattern of proteins obtained by the electrophoresis of human synovial fluid on agar plates at $\mathrm{pH} 8.6$ (Amido Black). (b) Precipitin pattern obtained by treating unstained plates as in (a) with rabbit antisera against human synovial fluid. After washing in saline the precipitin? lines were stained with Amido Black. (c) Precipitin pattern obtained by treating unstained plates as in (a) with rabbit antisera against rat liver and lysosomal membranes that had been pretreated with human synovial fluid. After washing in saline the precipitin lines were stained with Amido Black 
Table IV Effect of synovial fluid on the acid protease activity of polymorphonuclear leucocytes at $\mathrm{pH} 4 \cdot 0$

\begin{tabular}{|c|c|c|c|c|}
\hline Sample no. & $\begin{array}{l}1 \\
\mu g \text { Tyrosine } \\
\text { released by } \\
1 \text { ml polymorpho- } \\
\text { nuclear leucocytes } \\
\text { lysate }\end{array}$ & $\begin{array}{l}2 \\
\mu g \text { Tyrosine } \\
\text { released by } \\
1 \text { ml synovial fluid }\end{array}$ & $\begin{array}{l}3 \\
\mu g \text { Tyrosine } \\
\text { released by } \\
1 \text { ml synovial fluid }+ \\
1 \text { ml polymorpho- } \\
\text { nuclear lysate }\end{array}$ & $\begin{array}{l}\text { Per cent. } \\
\text { inhibition } \\
(1+2-3) / 3\end{array}$ \\
\hline $\begin{array}{l}15 \\
16 \\
17 \\
18 \\
19\end{array}$ & $\begin{array}{l}15 \cdot 4 \\
53 \cdot 0 \\
24 \cdot 4 \\
31 \cdot 5 \\
25 \cdot 1\end{array}$ & $\begin{array}{l}16 \cdot 3 \\
59 \cdot 8 \\
29 \cdot 2 \\
41 \cdot 4 \\
27 \cdot 2\end{array}$ & $\begin{array}{l}29 \cdot 2 \\
63 \cdot 2 \\
51 \\
51 \cdot 6 \\
53\end{array}$ & $\begin{array}{r}9 \\
78 \\
5 \\
41 \\
1\end{array}$ \\
\hline
\end{tabular}

Results are the mean values of three determinations.

\section{PROTEOLYTIC ACTIVITY OF SYNOVIAL FLUID}

\section{Acid protease activity}

The results are given in Table IV. Both the fluids and the cell lysate contain protease active at $\mathrm{pH} 4$ against haemoglobin. When mixed, the total activity of fluid plus cell lysate was not as great as expected in some of the samples. This could only be due to the action of an inhibitor. Possibly only some proteases were affected, since residual proteolytic activity was present both in fluids and cell lysate.

\section{Neutral protease ( $p H 7 \cdot 8)$}

The results of this experiment are given in Table $I$. Clearly the level of activity varied with the samples. The cells from these samples were not retained and so it was not possible to test the fluids for inhibitory action as in the acid protease experiments.

\section{Discussion}

The results in the paper show evidence for two types of endogenous anti-inflammatory activity being present in the synovial fluid of patients with rheumatic disease. One factor acts as a lysosomal membrane stabilizing substance. Further it has been shown that this latter factor is probably an $\alpha$ or $\beta$ globulin. If lysosomes and their proteases are mediators of inflammation then the role of the antiproteases and membrane stabilizing substances present must be anti-inflammatory. This paper has shown that the proteolytic activity of synovial fluid varies between patients. We have also shown that the proteases have an irritant effect on lysosomes. It appears that the clinical pattern of inflammation is the net balance of inflammatory factors (e.g. proteases) against antiinflammatory factors, two of which we have identified. It may be advantageous clinically to induce formation of these anti-inflammatory factors in the early stages of inflammation in order that the levels of these substances are in excess of irritants which act as mediators of inflammation.

Work by Barrett and Starkey (1973) with serum suggests that $\alpha_{2}$-macroglobulin may be a universal antiprotease. Further work is in progress in our laboratory in an attempt to identify the specific proteins, present in synovial fluid, responsible for the anti-inflammatory mechanisms we have reported. One such protein has been identified. Using rabbit antiserum to human $\alpha_{2}$-macroglobulin; $\alpha_{2}$-macroglobulin has been identified in some pathogenic synovial fluids.

In this communication we have reported the presence of two naturally occurring factors in pathological knee effusions whose biochemical properties suggest that they could be anti-inflammatory. It is as yet unknown how the levels of these factors may vary with the course of inflammatory disease and whether the severity of disease can be directly related to the concentrations of these factors. Work is in progress in an attempt to resolve these problems.

We wish to thank the Arthritis and Rheumatism Council for financial support, and Mr. R. Best for assistance with the immunological studies and Miss Mary Keeley for technical assistance with the acid phosphatase assays. We are indebted to Dr. D. Henderson and Mr. F. Ring of the Royal National Hospital for Rheumatic Diseases, Bath, for assistance in collecting the synovial fluid samples.

\section{References}

Anson, M. L. (1938) J. gen. Physiol., 22, 79 (Estimation of pepsin, trypsin, papain and cathepsin with hemoglobin)

Atkinson, D. C., Boura, A. L. A., AND Hicks, R. (1969) Europ. J. Pharmacol., 8, 348 (Observations on the pharmacological properties of inflammatory exudate)

Barrett, A. J., AND Starkey, P. M. (1973) Biochem. J., 133, 709 (The interaction of $\alpha_{2}$-macroglobulin with proteinases) 
Billingham, M. E. J., AND Robinson, B. V. (1972) Brit. J. Pharmacol., 44, 317 (Separation of irritancy from the anti-inflammatory component of inflammation exudate)

,,-- AND RoBson, J. M. (1969a) Brit. med.J., 2, 93 (Anti-inflammatory properties of human inflammatory exudate)

, - (1969b) Brit. J. Pharmacol., 35, 543 (Partial purification of the anti-inflammatory factor(s) in inflammatory exudate)

Collins, A. J., AND Lewis, D. A. (1971) Biochem. Pharmacol., 20, 251 (Lysosomal enzyme levels in the blood of arthritic rats)

Dingle, J. T. (1962) Proc. roy. Soc. Med., 55, 109 (Lysosomal enzymes and the degradation of cartilage matrix)

Di Pasquale, G., Girerd, R. J., Beach, V. L., and Steinetz, B. G. (1963) Amer. J. Physiol., 205, 1080 (Antiphlogistic action of granuloma pouch exudates in intact or adrenalectomized rats)

Ignarro, L. J., AND SLYWKA, J. (1972) Biochem. Pharmacol., 21, 875 (Changes in liver lysosome fragility, erythrocyte membrane stability, and local and systemic lysosomal enzyme levels in adjuvant-induced arthritis)

LeWIS, D. A., AND DAY, H. (1972) Ann. rheum. Dis., 31, 374 (Biochemical factors in the action of steroids on diseased joints in rheumatoid arthritis)

-, Symons, A. M., AND ANCILL, R. J. (1971) J. Pharm. Pharmacol., 22, 902 (The stabilization-lysis action of anti-inflammatory steroids on lysosomes)

Lowry, O. H., Rosebrough, N. J., FarR, A. L., and Randall, R. J. (1951) J. biol. Chem., 193, 265 (Protein measurement with folin phenol reagent)

Luscombe, M. (1963) Nature (Lond.), 197, 1010 (Acid phosphatase and catheptic activity in rheumatoid synovial tissue)

Menkin, V. (1942) Arch. Path., 34, 182 (Biochemical factors in inflammation and diabetes mellitus)

Persellin, R. H. (1972) Arthr. and Rheum., 15, 144 (Lysosome stabilization by adjuvant arthritis serum)

Rinderknecht, H., Geokas, M. C., Silverman, P., Lillard, Y., and Haverback, B. J. (1968) Clin. chim. Acta, 19, 327 (New methods for the determination of elastase)

Symons, A. M., LewIS, D. A., ANd ANCILl, R. J. (1969) Biochem. Pharmacol., 18, 2581 (Stabilising action of antiinflammatory steroids on lysosomes)

UNGAR, G. (1947) Lancet, 2, 708 (Release of proteolytic enzyme in anaphylactic and peptone shock in vitro) 